\title{
REVISIONES PROCESALES PARA UN COMPLIANCE BASADO EN EL MODELO DE RESPONSABILIDAD PENAL EN EL ECUADOR $^{1}$
}

\author{
Mauricio EnRiQue PACHeco ${ }^{2}$ \\ UNIVERSIDAD CENTRAL DEL ECUADOR, QUITO - ECUADOR
}

\section{RESUMEN:}

Las publicaciones de autores ecuatorianos sobre el tema de la responsabilidad penal de las personas jurídicas son prácticamente inexistentes. De los escasos trabajos revisados, ninguno aborda, con cierta minuciosidad, el tema del modelo de responsabilidad corporativa y el compliance, ni sobre la determinación del alcance y significado de los principios informadores del Derecho procesal penal desde la criminalización primaria.

Frente a esta previsible problemática, generada por el Legislador ecuatoriano y que ha sido objeto de una irremediable falta de atención de los estudiosos del Derecho penal en nuestra realidad, invocamos los criterios y las opiniones de los grandes penalistas

1 Artículo recibido el 23 de octubre de 2019 y aprobado el 24 de noviembre de 2019

2 Profesor Adjunto II y Catedrático de Derecho penal y Derecho procesal penal de la Facultad de Jurisprudencia de la Universidad Central del Ecuador. ORCID: 0000-0001-7957-6480 
europeos y principalmente de autores españoles que han contribuido vigorosamente en el desarrollo de criterios claros, racionales y prácticos para el procesamiento penal de las personas jurídicas, en el marco de las garantías constitucionales de las que son titulares las personas jurídicas. La cuestión sobre la utilidad procesal de la adopción de los programas de compliance en la determinación de, si en un modelo de responsabilidad, por hecho propio, su mera existencia y su efectividad tienen consecuencias atenuantes o eximentes de culpabilidad y cuál debería ser el tratamiento, en relación con el principio acusatorio y el principio de presunción de inocencia, vigentes en el ordenamiento jurídico ecuatoriano.

\section{PALABRAS ClAVE:}

Compliance, responsabilidad penal de las personas jurídicas, carga de la prueba, principio acusatorio, proceso penal

\section{ABSTRACT:}

The publications of Ecuadorian authors on the issue of criminal liability of legal persons are practically non-existent. Of the few works reviewed, none addresses, with some thoroughness, the issue of the corporate responsibility model and compliance, nor on the determination of the scope and meaning of the reporting principles of criminal procedural law since primary criminalization.

Faced with this foreseeable problem, generated by the Ecuadorian Legislator and that has been the subject of an irremediable lack of attention of criminal law scholars in our reality, we invoke the criteria and opinions of the great European criminalists and 
mainly of Spanish authors, who have vigorously contributed to the development of clear, rational, and practical criteria for the criminal prosecution of legal persons within the framework of the constitutional guarantees of which legal persons are holders. The question of the procedural utility of the adoption of compliance programs in determining whether in a model of responsibility, in their own right, their mere existence and their effectiveness have mitigating or exempt consequences of guilt and what the treatment should be in relation with the accusatory principle and the principle of presumption of innocence in force in the Ecuadorian legal system.

\section{KEYWORDS:}

Compliance, criminal liability of legal persons, burden of proof, accusatory principle, criminal proceedings 


\section{Ideasgeneralesparaeldiseño de un compliance aplicable como eximente $o$ atenuante de la responsabilidad penal de las personas jurídicas en el Ecuador}

\section{I.A. Compliance y la responsabilidad penal de la persona jurídica}

Debe ser un programa que tenga como objetivo central no solo la existencia de una estructura preventiva de detección y de denuncia de las infracciones penales a las autoridades públicas después de cometido o incrementado un riesgo para los bienes jurídicos amparados por la Ley, sino que, además, importe una actividad institucional, que propenda la fidelidad al Derecho ${ }^{3}$. Pero agregaría otro objetivo: el constituir a los programas de cumplimiento como elementos eximentes o de atenuación de la RPPJ, orientados a validar o legitimar la relación existente entre la capacidad autorregulatoria privada y la potestad estatal de control corporativo. En otras palabras, se debe superar la duda sobre si el compliance program es o no objeto de prueba, en la determinación de responsabilidad penal corporativa, en un modelo de responsabilidad propio propuesto antes en términos generales.

3 Es muy claro este autor al resaltar que el compliance no solo debe implementarse para evitar riesgos provenientes de las conductas de los trabajadores, sino también de los dirigentes, a fin de que cumplan conlosmandatos y prohibicionesjurídico-penales, su descubrimiento y sanción. Coca Vila. 2013, p. 54; Bajo Fernández, M., y Gómez JaraDiez, C. "Derechos procesales fundamentales de la persona jurídica", en Bajo Fernández, M., et al. Tratado de la responsabilidad penal de las personas jurídicas. Pamplona, Editorial Aranzadi S.A., 2012, p. 281. 
Este articulo pretende demostrar que la no existencia de compatibilidad entre el sistema de imputación vicarial y el compliance, como instrumento explicativo de la responsabilidad penal corporativa, no es posible, dadas las estructuras dogmáticas y procedimentales diferentes y que, por el contrario, si utilizamos el modelo de responsabilidad corporativa, por hecho propio, los programas de cumplimiento vienen a constituirse en el insumo principal del proceso penal de imputación a la organización.

Utilizaremos como metodología ciertos elementos del modelo planteado por $\mathrm{Nieto}^{4}$, el cual tiene la característica de permitir, con una aceptable flexibilidad, insertar el programa del compliance en el sistema de responsabilidad penal propio para las personas jurídicas.

La propuesta elaborada de NiETO MARTín toma en cuenta una serie de presupuestos, que deben irse adaptando a las realidades de cada ordenamiento jurídico. Analicemos brevemente las principales.

\section{I.A. 1. Un modelo de responsabilidad más internacional y aceptable}

Las categorías del delito tienen su fuente en la dogmática penal alemana, que no es muy extendida en todo el mundo y más bien tienen una cobertura muy restringida. Por ello, NIETO ${ }^{5}$ sugiere que hay que tener muy en cuenta que las estructuras productivas y financieras de las corporaciones, tienen cada vez más connotación internacional y transfronteriza, regidas por distintos

\footnotetext{
4 Nieto Martín. 2013i, p. 36.

5 Ibíd.p. 20.
} 
ordenamientos jurídicos, dada la multiplicidad de procesos, que constituyen la cadena de desarrollo de las actividades productivas o de servicios prestados por la organización ${ }^{6}$. Enfocarnos en modelos particulares, que no responden a las líneas generales trazadas por el Derecho comparado en Europa y en Latinoamérica, no nos serviría de mucho para futuros desarrollos dogmáticos, que los vayan perfeccionando.

\section{A. 2. Programas de cumplimiento orientados a la prevención}

Entendamos que un programa de cumplimiento tiene dos modalidades, que pueden adoptar las corporaciones, cada una con consecuencias diferentes: los jueces deben, en primer lugar, comprender los alcances del programa de cumplimiento para, de acuerdo con ello, determinar el grado de eficacia en el control preventivo de las infracciones. Como ya anticipamos, existen dos grandes modelos de compliance: los modelos de vigilancia y el modelo del código ético.

El modelo de código de conducta o ético se estructura sobre una base de medidas normativas, de carácter preventivo, orientadas a generar sentimientos solidarios y un ambiente propicio para el desarrollo de una conciencia ética social de los empleados y funcionarios de la persona jurídica, a través del proceso de formación constante dentro de la corporación. El control debe realizase permanentemente, a través de la verificación de la

6 Gracia Martín, L. “El Derecho penal ante la globalización económica", en Cuestiones de Derecho penal, procesal penal y política criminal. Lima, ARA Editores, 2010, p. 85. 
aplicación de ciertas regulaciones, ciertos principios y valores, que identifiquen todas las actividades que desarrolla la empresa, tales como la contratación de personal, el tipo de proveedores, la atención al cliente, etc.

En consecuencia, dentro de un modelo de valores éticos, lo recomendable, en la denuncia de los actos irregulares, es que no debe ser anónima, sino reservada. La confidencialidad en la denuncia denota una orientación, por el cultivo de valores, que, a diferencia del anonimato, no da lugar a posturas abusivas de autoridad, la cual termina prefiriendo el control por el control. Esta especie de cívica corporativa prefiere la confidencialidad antes que el anonimato, para alejarse de prácticas colaboracionistas con aquellos regímenes autoritarios que terminaron convirtiendo a las empresas en centros ilegales de obtención de información y delación, utilizada para procesos persecutorios en contra de empleados y funcionarios de las organizaciones jurídicas.

Un sistema de control con orientación a los valores concibe a las sanciones como un asunto de mínima intervención y de última instancia, con el máximo respeto a las reglas del debido proceso, con penas proporcionales y segundas oportunidades, apostando por sanciones que estén individualizadas ${ }^{7}$. No son solo modelos de prevención de delitos, sino que su implementación, debe tener efectos que vayan mucho más allá de la línea preventiva penal y adquiera otras connotaciones,

7 GonZÁLEZ, A. “Autorregulación empresarial, ordenamiento jurídico y Derecho penal. Pasado, presente y futuro de los límites jurídico penales al libre mercado y a la libertad de empresa", en MONTANER FERnÁndeZ, R. (coord.). Criminalidad de la empresa y compliance. Prevención y reacciones corporativas. Barcelona, Editorial Atelier, 2013, pp. 77-110. 
ligadas a la construcción de culturas ético legales en el desempeño corporativo ${ }^{8}$.

\section{A. 3. Consenso y programas de cumplimiento basados en valores}

No significa desconocer la influencia de los directivos de la empresa, sino generar códigos de comportamientos, que no sean la expresión de los intereses unilaterales del empleador o de los directivos, ni producto de la imposición de voluntades en desmedro de los intereses y los derechos de los trabajadores, que podrían verse muy afectados. En materia judicial, existe la presencia de un código de comportamiento con índices bajos de credibilidad y confianza.

Igual tratamiento debería darse a la elección de los órganos de vigilancia. El modelo constructivo de valores generalmente debería tener representantes de los trabajadores y empleados para ganar legitimidad y credibilidad. Los modelos de vigilancia

8 Dice SIERRA LeWIN que: [...] esa cultura debe ser forjada a través del hábito, cosa que solo se logra alineando los incentivos de cada individuo. Por ejemplo, si se premia a las personas solo por obtener más clientes o incrementar la participación de mercado de la compañía, se generan razones para conseguir estos objetivos a cualquier precio. Por lo tanto es deber de las mismas organizaciones establecer el camino que deben seguir sus empleados para lograr los objetivos de la institución, poniendo énfasis en el cómo en el lugar del qué, vinculando la rectitud de los medios a los incentivos dados [...]. Sierra Lewin, S. 2017; Neira Peña, A. M. "La persona jurídica como nuevo sujeto pasivo del proceso penal en los ordenamientos chileno y español". Revista de Derecho - Universidad Católica del Norte. 2014, p. 21. Disponible en la siguiente página web: http:/ / www.redalyc.org/articulo.oa?id=371041329005. ISSN 0717-5345. (última consulta 21 de junio de 2018) 
suelen estar constituidos por representantes exclusivos de los empleadores o directivos de la corporación, muy lejos de la necesidad de independencia, que deben caracterizarlos, para que el programa sea viable y efectivo.

La importancia de un sistema más democratizado y abierto, a la hora del diseño y la implementación de los programas de cumplimiento, tiene repercusiones importantes al emplearlos como elemento de descargo en los procesos en los que está en juego la responsabilidad penal de las personas jurídicas. En este sentido, NiETO MARTín recalca: [...] que un programa de cumplimiento basado en estas ideas supondría una respuesta adecuada a los problemas de legitimación, que desde siempre arrastra la autorregulación empresarial y que, sin duda alguna, conseguirán una mayor adhesión de los empleados a los valores y política de la empresa y [...] la introducción de la responsabilidad penal de las personas jurídicas, sin un incremento de la legitimidad de las decisiones empresariales y de la accountability de sus responsables [...].

\section{B. Exigencias procesales para la incorporación del compliance en el proceso penal ecuatoriano}

\section{B. 1. El compliance y el sistema vicarial}

En nuestro caso, la incorporación del compliance, como objeto de prueba, dependerá de la valoración que éste adquiera, dentro de la normativa procesal penal interna, para determinar la responsabilidad penal de las organizaciones jurídicas.

En el actual sistema vicarial extremo, quien haya adoptado un compliance preventivo, aplicado a la corporación, nos atrevemos 
a decir que ha perdido su tiempo, si piensa obtener algún tipo de beneficio o benevolencia procesal a la hora de la imputación penal en contra de la persona jurídica.

Es un acto que resulta intrascendente, para efectos de valoración probatoria, en la determinación de la responsabilidad penal de las personas jurídicas. No constituye objeto de análisis, ni de estudio y la incorporación probablemente podría eventualmente ser tomada en cuenta por el juez penal, con el objeto de elegir una pena modulada, dentro de los parámetros de referencia que le otorga el mismo CoIP, según sea el tipo de delito cometido.

Esto es verdad porque el proceso penal, que se inicia en contra de la persona física, versa sobre la actuación típica, antijurídica y culpable del individuo infractor, sin importar, si su conducta estuvo enmarcada o no dentro de un sistema autorregulatorio o de prevención penal, en razón de que la adopción del compliance, no lo hace la persona física, a título personal, sino que es un acto corporativo, propio de una voluntad organizacional, que no está en juego, ni es revisable dentro del proceso penal.

Pero si tenemos un régimen de responsabilidad propia de las corporaciones, que se propone en estos capítulos finales, la existencia de los programas de compliance resulta por demás determinante a la hora de la imputación penal, porque su existencia efectiva supone que la empresa ha emprendido tareas de supervisión, vigilancia y control de todos sus funcionarios y trabajadores para realizar sus actividades, dentro del marco de riesgos permitidos por la legislación interna y externa, lo que significa que la organización ha adoptado una política de prevención de delitos?

9 Feijóo SÁnchez, B. “Fortalezas, debilidades y perspectivas de la responsabilidadpenal de las sociedades mercantiles", en OLIVEROS 
Es decir, la existencia del compliance penal al interior de la corporación puede significar una posible causa automática de exclusión, exoneración y atenuación de la responsabilidad. Lo determinante, dice NeIRA PEÑA, [...] para decidir sobre la responsabilidad penal de las personas jurídicas es el efectivo cumplimiento de los deberes de supervisión y control sobre sus actividades, sin perjuicio de que la existencia de tales programas preventivos sirva para protocolizar o formalizar tales controles $y$, por ende, como indicio de cumplimiento $[. . .]^{10}$.

\section{B. 2. El compliance debe estar documentado}

La idea, que se concreta, deviene de tener en cuenta que la existencia del compliance, no puede constituirse en un muro de protección de la persona jurídica, ante la eventualidad de ser responsabilizada penalmente, frente a la comisión de una infracción penal, porque resulta forzado presumir que existen medidas eficaces de prevención por la evidencia escrita de un programa de cumplimiento o -compliance-.

De allí que, en caso de existir un compliance, debemos concretar la forma en que este programa de prevención debe ser admitido en el proceso penal. Lo primero que se nos ocurre, a fin de que sea un aporte probatorio, es la presentación por escrito del programa implementado, debidamente certificado y aprobado por las autoridades administrativas internas y del Estado, de

Alonso, M. (coord.). La responsabilidad penal de las personas jurídicas. Fortalezas, debilidades y perspectivas de cara al futuro. Valencia, Editorial Tirant lo Blanch, 2014, p. 149. Véase también en la siguiente página web: http://www.corteidh.or.cr/tablas/usuario/francisco.pdf.

NeIra PeÑa. 2017, p. 283. 
ser necesario e indispensable. El documento debe contener todos los mecanismos, actualmente estandarizados sobre su funcionamiento, implementación y de retroalimentación ${ }^{11}$.

La prueba de la existencia formal del documento de compliance debe estar obligatoriamente acompañada de la prueba de verificación de la efectividad de éste en el funcionamiento de la corporación. El otorgamiento de la calidad de atenuante a los programas de cumplimiento no se sustenta en declaraciones o discursos declarativos y teóricos, sino del seguimiento documental o digital de la actividad del compliance.

En otras palabras, la constancia del funcionamiento de los programas de cumplimiento deben estar debidamente documentados y registrados por las evidencias y constataciones diarias de los diferentes organismos, encargados de su seguimiento e implementación, los comentarios y sugerencias, así como las

11 La autora esboza un cuadro descriptivo de los contenidos generales del compliance. Dice: [...] en primer lugar, el programa de cumplimiento deberá ser aportado al proceso como prueba documental, en tanto que deberá encontrase documentado. En tal soporte, figurara, de ordinario, el código ético de la entidad, su mapa de riesgos delictivos, el diseño de su modelo de organización y gestión pre ordenado a evitar delitos, los protocolos de actuación orientados a prevenir y detectar la comisión de ilícitos, los procedimientos que concreten el proceso de formación de la voluntad de la persona jurídica, de adopción de decisiones y de ejecución de las mismas, la configuración y las funciones del organismo encargado del funcionamiento del programa, el sistema disciplinario, el diseño de un canal de denuncias, las labores de comunicación y formación diseñadas para dar a conocer el modelo entre los distintos agentes que se relacionan con la entidad, así como el sistema según el cual se actualizará y adoptará el programa a los cambios de la organización de la entidad o a los que, de otro modo, afecten a la determinación de los riesgos a prevenir [...]. NEIRA PeÑa. 2017, p. 283. 
recomendaciones realizadas por los oficiales de cumplimiento y la forma cómo fueron atendidos estos requerimientos. De esta manera, se construye lo que se denomina cultura de cumplimiento de la legalidad. De ello se deduce que: [...] la entidad que cuenta con un programa de cumplimiento eficaz, podrá usarlo para ir preconstituyendo pruebas, que le podrán servir para atenuar la responsabilidad, ya sea a través de la acreditación de la operatividad del programa en cuestión [...], ya sea por la vía de aportar pruebas nuevas y decisivas para esclarecer las responsabilidades penales $[. . .]^{12}$.

Pero la acreditación como prueba del modelo de cumplimiento también puede ser validada, mediante pruebas periciales testimoniales de empleados, dirigentes, administradores, contratistas, proveedores y hasta consumidores. Sin embargo, las pruebas periciales, a la hora de determinar la efectividad del compliance, son las más apropiadas, porque implican una constatación de los hechos, documentos y la actividad de la corporación, que en forma conjunta y sistematizada, son idóneas o no para prevenir o minimizar las consecuencias de los hechos delictivos. Para algunos autores, este tipo de experticias son las únicas que sirven para acreditar o desacreditar la cultura de cumplimiento de la legalidad en una corporación ${ }^{13}$.

\footnotetext{
12 Neira Peña. 2017, pp. 284-285.

13 Ibíd. p. 286.
} 


\section{B.3. ¿Los programas de compliance excluyen la responsabilidad penal de las personas jurídicas?}

La controversia sobre la existencia del compliance, como elemento constitutivo de exoneración de la responsabilidad penal de las corporaciones, desplaza hacia la persona jurídica acusada la carga probatoria, la cual debe demostrar la existencia de un programa auto regulatorio, elaborado bajo premisas y exigencias normativas generales, y como consecuencia, evidenciar ser una organización no peligrosa en el desempeño de sus actividades y cumplidora con el orden jurídico. La razón es la misma que se aplica en relación con la carga dinámica de la prueba y son las organizaciones jurídicas las que tienen mayor acceso, mejor posición y la posesión de los elementos probatorios, las que deben presentar esa prueba.

NeIRA Peña estima que es posible trasladar la carga de la prueba de la existencia del compliance a la persona jurídica acusada, porque la inexistencia del programa podría considerarse como un indicio de tal condición. Esta autora realiza una serie de matizaciones para precisar y diferenciar dos situaciones un tanto complicadas: la primera, considera al delito, cometido por los administradores y propietarios, como un indicio de que el compliance no funcionó, y que, por tanto, corresponde a la entidad demostrar con pruebas ciertas que sí tomó todas las previsiones para evitar tal resultado lesivo, en razón de que los deberes de control y vigilancia están en manos de quienes ejecutaron la conducta ilícita. Pero si el delito lo comete un empleado o trabajador de menor jerarquía dentro de la empresa, entonces la carga indiciaria no es tan fuerte como cuando lo comete el funcionario, que 
se encuentra en la cúpula de la administración de la persona jurídica $^{14}$ y la carga de la prueba se traslada a la Fiscalía.

En este sentido, si el delito lo cometen los subordinados de la corporación, entonces la carga indiciaria es menor y la Fiscalía debe demostrar la inexistencia o ineficacia de un programa de compliance. Por el contrario, si el delito lo cometen los miembros de la alta cúpula de la corporación, es decir, quienes la dirigen, entonces este hecho constituye un indicio determinante de la ausencia de un programa auto regulatorio eficaz para la prevención de delitos. Esta situación demostraría el déficit preventivo de la corporación, sin que esta apreciación constituya una violación al principio de legalidad. No llegaríamos a este resultado, si se insiste en que la Fiscalía sea quien tenga la carga de demostrar la ausencia de un programa de prevención.

Claro que la presunción debe reunir ciertos requisitos, a fin de evitar la afectación al principio de inocencia, tales como el inferir que si los dirigentes cometen el delito, entonces no había control, ni supervisión en la corporación, y, por ende, el programa de autorregulación no era eficaz. Por otro lado, la corporación cuenta con derecho de destruir la presunción iuris

14 Dice la autora que: [...] cuando delinque un subalterno, la carga de indicios frente a la persona jurídica no es tan fuerte $y$, en tal caso, el MF tendrá que ser más diligente a la hora de hacer indagaciones sobre la ausencia de los debidos controles, por parte de la entidad, buscando otras pruebas e indicios para acreditar la ineficacia del modelo de prevención. Sin embargo, cuando delinque el delincuente, parece aceptable recurrir a presunciones legales, como la establecida por la regulación italiana, según la cual, para el caso en que delinquen los dirigentes, se presumen iuris tantum que los programas de cumplimiento eran ineficaces y es la empresa la que debe probar que contaba con medidas adecuadas para prevenir los delitos cometidos [...]. Neira Peña. 2017, pp. 287-288. 
tatum, demostrando que hubo un premeditado y fraudulento desacato a las previsiones de un programa de compliance interno de la empresa ${ }^{15}$.

\section{El compliance y el régimen de responsabilidad por hecho propio, que cumplan las exigencias de los principios básicos del Derecho penal}

En este sentido, son válidas las resoluciones de las máximas autoridades judiciales españolas, quienes nos llevan enorme ventaja sobre las previsiones que se deben tomaren el largo proceso de concreción de un sistema más garantista de tratamiento penal en contra de las personas jurídicas. Hemos tomado de referencia algunas sentencias emblemáticas de los tribunales españoles ${ }^{16}$, comentadas por varios prestigiosos penalistas, en relación con

15 NeIRA Peña señala que: Por otra parte, cuando delinquen los dirigentes la posibilidad de inferir la ineficacia del programa de cumplimiento de su implicación en el delito es mayor, dada la mayor fuerza incriminatoria que, para la persona jurídica, tiene la implicación de sus altos cargos en la actuación delictiva. Por eso, en este caso, se propone que se produzca una presunción legal que establezca la inefectividad de las medidas de prevención para el caso de que los encargados de la dirección y el control del ente hayan delinquido. Ahora bien, para que esta presunción, basada en un nexo lógico, la presunción de inocencia del ente, es necesario que se configure con carácter iuris tantum, permitiendo a la entidad desvirtuar tal presunción [...]. NeIRA PEÑA. 2017, pp. 287-288

Especialmente las siguientes sentencias y resoluciones: Sentencia del TS, de 2 de septiembre de 2015; Sentencia del Pleno de la II Sala del Tribunal Supremo, de 29 de febrero de 2016; Sentencia del Tribunal Supremo, de 16 de marzo de 2016; Sentencia del Tribunal Supremo, de 3 de noviembre de 2016; Circular de la Fiscalía General del Estado, de enero de 2011; y, Circular de la Fiscalía General del Estado, de enero de 2016. 
el ejercicio punitivo, en materia de responsabilidad penal, de las personas jurídicas.

\section{A. Tener cuidado de la aplicación automática}

Si de algo se deben alejar los aplicadores de justicia penal, en materia de responsabilidad penal, de las personas jurídicas, es la imposición de fallos judiciales automáticos y cargados de elementos, que definan la proscrita responsabilidad penal objetiva. Este fenómeno fue muy evidenciado en la justicia española, en numerosas ocasiones ${ }^{17}$, por tal motivo, el Tribunal Supremo tuvo que salir al paso para enderezar la cuestión por la vía de la jurisprudencia.

La sentencia de 2 de septiembre de 2015, emitida por el Tribunal Supremo español, rescata esta advertencia, que nos puede servir de mucho para nuestro modelo propuesto. Se refiere a que bien sea tratándose de un modelo vicarial o un modelo de responsabilidad propio, los hechos deben describirse en función de quien los cometió y de la forma cómo lo hizo. No puede haber una atribución del delito a la persona jurídica, a partir de la narración y de la descripción de los hechos cometidos por la persona física; es decir, no puede haber ausencia de referencia de los hechos atribuidos a la corporación, como sujeto activo del delito, puesto que provoca una ausencia de la ratio decidendi en la decisión de los jueces.

Es importante el señalamiento sobre la independencia de los hechos, que van a servir de fundamento de la imputación

17 Gómez-Jara Diez, C. El Tribunal Supremo ante la Responsabilidad penal de las personas jurídicas. Pamplona, Aranzadi, 2017, p. 30. 
penal. El principio de personalidad del acto implica una clara diferenciación de los presupuestos de hecho al rato de evaluar la responsabilidad penal por parte del juez ${ }^{18}$. En un sistema de responsabilidad propio de la persona jurídica, no deben darse estos traslados de responsabilidad corporativa, desde la actuación o desde los hechos atribuidos a la conducta de la persona física, sino desde los actos cometidos por la persona jurídica.

\section{B. La culpabilidad corporativa independiente de la culpabilidad individual}

La condenaa la persona jurídica deberealizarse como consecuencia de la declaración de culpabilidad de la corporación y ésta, a su vez, debe provenir como consecuencia de la infracción cometida por la organización, en un proceso incoado con las garantías constitucionales previstas para todo proceso penal; es decir, es una exigencia la diferenciación que debe tener la culpabilidad de la persona natural y la culpabilidad de la corporación.

En el sistema de responsabilidad propuesto (sistema mixto), si bien es cierto que la infracción penal debe provenir del accionar de la persona física, que tenga alguna relación laboral, contractual, administrativa o de propiedad, el fundamento de la responsabilidad penal corporativa debe ser independiente del fundamento de

En relación con la sentencia, de 2 de septiembre des 2015, sobre el caso de un delito de estafa, dice, respecto de la sentencia casada: Con independencia para casar la sentencia de instancia respecto de la persona física, basado en el vacío probatorio de los elementos definitorios del delito de estafa [...] se puede evidenciar que la condena de la persona jurídica se deriva de un automatismo objetivista más propio de una declaración de responsabilidad civil [...] que una declaración de responsabilidad penal [...]. Ibíd. p. 33. 
la imputación penal de la persona física. Reconocemos que no pretendemos un modelo de autorresponsabilidad absoluta porque no se puede prescindir por completo de una conducta de la persona física, que es quien comete la infracción penal, que tiene la virtud de generar responsabilidad punitiva a la persona humana y también, por otros hechos derivados de esta conducta y que no son los mismos, acarrea la responsabilidad corporativa ${ }^{19}$.

La culpabilidad penal, en términos generales, debería tener tres presupuestos, que deben necesariamente que verificarse:

1. Una conducta delictiva de la persona física, relacionada con la corporación y que produzca efectos beneficiosos a la entidad;

2. Una infracción a los deberes de supervisión, vigilancia y control, que tenga como consecuencia directa y muy probable la realización del resultado lesivo; y,

3. Un defecto organizativo y estructural, relacionado con políticas de implementación de sistemas de cumplimiento eficaz de la legalidad.

Lo importante y el paso adelante en el sistema propuesto, tomado de autores, tales como Gómez JARA, Nieto Martín, Zugaldía Espinar ${ }^{20}$ y, sobre todo, Feijóo SÁnchez, se refiere

19 Feijóo SÁnCheZ, B. 2017, p. 102.

20 Zugaldí́a Espinar, J. "La admisión de la responsabilidad penal de las personas jurídicas: un pilar básico del moderno Derecho penal económico", en Mir Puig, S., Modolell González, J., Gallego Soler, J., y Bello Rengifo, C. (coords.). Estudios de Derecho penal económico. 
a superar el criterio de que el defecto de la organización, es el referente material para la determinación de la persona jurídica. La culpabilidad de ésta se debe configurar, a partir del defecto organizativo estructural, relacionado con políticas o programas de cumplimiento de la legalidad [...], que supera el concepto de defecto organizativo por falta de control.

FEIJóo SÁNCHEZ ${ }^{21}$ pone un ejemplo en los siguientes términos: $\mathrm{Si}$ un alto directivo de una empresa, mediante sobornos a funcionarios públicos, consigue contratos para la empresa gracias a la falta o ausencia de control organizativo; si los administradores no controlaron estas actuaciones, entonces existiría delito corporativo. Pero si el oficial de cumplimiento de la empresa detecta estas anomalías, investiga y descubre este procedimiento ilegal, denunciando a las autoridades de la Fiscalía, estamos frente a un hecho, en el que, existiendo un defecto de organización por falta de control, no existiría un defecto organizativo estructural, porque la empresa demostró tener un buen modelo efectivo de compliance o de cumplimiento con la ley. En conclusión, la falta de una cultura de cumplimiento de la legalidad, en ese caso concreto, con la ausencia de un compliance efectivo es una falta atribuible a la corporación. Podríamos estar frente a un hecho propio, que acarrea culpabilidad empresarial.

Caracas, Editorial Librosca, 2002, pp. 123-196.

21 Feijóo SÁnchez, B. 2017, p. 127. 


\section{C. Los principios fundamentales del Derecho penal deberán ser observados en cualquier decisión, que determine la responsabilidad corporativa}

Extraemos esta máxima de la Sentencia, de 2 de septiembre de 2015, emitida por el Tribunal Supremo de España y que determina que cualquiera que sea el modelo de responsabilidad penal que opte un determinado ordenamiento jurídico, la aplicación de aquel sistema debe informarse de los principios fundamentales del Derecho penal.

Los planteamientos que conduzcan a la determinación de la responsabilidad corporativa deberán ajustarse a la exigencia mínima de responsabilidad personal, por la cual cada persona responde por sus propios actos y no por las infracciones de terceros. La culpabilidad del ente colectivo no puede fundamentarse en las actuaciones de las personas físicas, que cometieron la infracción, porque de darse esta situación se trataría de un sistema de responsabilidad objetiva, en el que los presupuestos fácticos del funcionario o empleado de la corporación, se transforman en los presupuestos de la imputación de la organización.

En este sentido, Gómez JARA ${ }^{22}$ recalca que el modelo de responsabilidad, por hecho propio, es un modelo mucho más aceptable, en términos prácticos, porque guarda una proporción mayor de conformidad con los principios fundamentales tributarios del Derecho penal tradicional. Sin embargo, no deja de cuestionar la asimetría entre las exigencias mayores de la conducta de la persona física y la conducta de la persona jurídica.

22 Gómez-Jara Diez. 2017, pp. 41-43. 


\section{D. EI delito de la persona física debe ser un presupuesto y no el fundamento de la responsabilidad penal de la corporación}

En un régimen de autoresponsabilidad o por hecho propio, los hechos que configuran el tipo penal de la persona física no son, ni deben ser aquéllos que configuran la tipicidad de la persona jurídica. Una reciente sentencia de los tribunales españoles ${ }^{23}$ establecía que la infracción de la persona natural [...] opera como requisito precedente necesario para el ulterior pronunciamiento de la responsabilidad penal propia de la entidad, medida en términos de incumplimiento de la obligación de poner los medios para evitar la comisión de delitos en su seno $[. . .]^{24}$.

Esta afirmación nos permite solucionar problemas que, desde la óptica del sistema vicarial, fueran imposible hacerlo. Por ejemplo, si la conducta de la persona humana fuera el fundamento de la responsabilidad penal, de tal forma que no existiendo conducta humana, no habría conducta de la organización, entonces en el caso en que una persona física falleciera, o no existiera o simplemente fuera difícil identificarla y no se pudiere dirigir el proceso en su contra, la consecuencia lógica sería la imposibilidad de establecer la responsabilidad penal de las personas jurídicas, porque desaparecería el fundamento de la culpabilidad corporativa, creando lagunas de impunidad, que es lo que precisamente se trata de superar con el modelo de responsabilidad por hecho propio ${ }^{25}$.

23 Tribunal Supremo de España, sentencia del Pleno de la II Sala, de 29 de febrero de 2016.

24 Gómez-Jara Diez. 2017, p. 57.

25 Silva SÁnChEZ, J. M. “Responsabilidad penal de las personas jurídicas 
Ahora, en el modelo de autorresponsabilidad ideal, que se propone para la legislación ecuatoriana, el centro gravitacional alrededor del cual gira la imputación a la persona jurídica debe ser un hecho propio de la corporación, que se constituya en un factor propio de la responsabilidad penal ${ }^{26}$. El defecto estructural aparentemente deviene en uno de los sistemas más adecuados de culpabilidad colectiva, que supera el modelo vicarial de transferencia.

En este sentido, la implementación de políticas de cumplimiento de la legalidad al interior de las corporaciones constituiría un importante elemento de definición de la responsabilidad penal. En palabras de FeIJoó SÁnchez: [...] el delito individual sin políticas de cumplimiento de la legalidad puede ser definido como un delito corporativo [...]. El cumplimiento de la legalidad en todos los ámbitos de la actividad y gestión empresarial es el elemento estructural por el que debe velar la persona jurídica. Si lo ha hecho es algo que debe constatarse con los medios habituales de prueba, incluyendo aquélla que se pueda realizar mediante indicios $[\ldots]^{27}$.

De tal forma que se descarta que el mero defecto organizativo por la deficiente gestión pueda ser el origen y el sustento de la responsabilidad penal corporativa, en razón principalmente de que el defecto de organización, no es un hecho, sino un acto de carácter valorativo, que no tiene conexión con el resultado

en el Derecho español", en Montaner Fernández, R. (coord.). Criminalidad de empresa y compliance. Prevención y reacciones corporativas". Barcelona, Editorial Atelier, 2013, p. 32.

Feijóo SÁnchez. 2017, p. 127.

Ibíd. p. 129. 
lesivo ${ }^{28}$. Se requiere el hecho individual cometido por la persona física más la existencia del defecto organizativo y, finalmente, la constatación del defecto estructural como elementos integradores y constitutivos del hecho propio. En este contexto, los programas de cumplimiento o compliance programs pueden resultar insatisfactorios a la hora de haber evitado la comisión de un delito.

Sin embargo, tampoco sería suficiente motivo de imputación a la corporación, la evidencia de un fallo organizacional, porque material y constitucionalmente es imposible establecer mecanismos de control y vigilancia total sobre los empleados y funcionarios, que reduzcan a cero las posibilidades de realizaciones delictivas. Debe analizarse la predisposición de la corporación para activar dispositivos de reacción, que denoten una cultura organizacional de cumplimiento de la legalidad para evitar investigar, denunciar y sancionar los delitos en la empresa ${ }^{29}$.

28 Gómez Tomillo, M. Introducción a la Responsabilidad Penal de las Personas Jurídicas. Pamplona, Editorial Aranzadi, 2015, p. 73.

29 En la nueva legislación española, GÓMEZ-JARA y FEIJÓO SÁNCHEZ llegan a coincidir en la cultura de cumplimiento de la legalidad como efecto determinante en la responsabilidad penal de la persona jurídica, a partir de un hecho propio. GÓMEZ-JARA resalta aún más la importancia del compliance en este modelo. Dice: [...] Quizá aún más relevante desde una perspectiva global es que tanto el Pleno del Tribunal Supremo como la Circular 1/2016 se alienan con la indiscutible tendencia internacional en materia de compliance. Por motivos de espacio no podemos extendernos aquí en esta cuestión; no obstante, en esta cuestión puede afirmarse que los estándares internacionales de compliance hacen gravitar el centro de cualquier sistema de gestión de compliance en el establecimiento de una cultura de compliance [...]. La reforma operada por la LO 1/2015 [...] resulta coherente cuando el Tribunal Supremo haya pretendido centrar la atención en lo que, a nivel de estandarización internacional, se considera decisivo para determinar la eficacia de los modelos o el sistema de compliance 
Solo en caso de ausencia de una cultura corporativa, vendría a configurarse la existencia de una falla estructural. La evidencia sobre estos tres elementos configuraría el hecho propio, que fundamentaría la responsabilidad penal de la persona jurídica.

\section{E. Las garantías procesales de la corporación no deben ser disminuidas frente a las garantías procesales de las personas físicas}

Ese principio es evidente cuando el derecho a la tutela judicial efectiva y el reconocimiento de todos los derechos constitucionales se hace efectivo en la normativa legal y constitucional. La persona jurídica es titular de todos los derechos fundamentales, cuantitativa y cualitativamente, en los mismos términos de los que gozan las personas naturales, amparada por el principio de igualdad ante la ley. Es decir, gozan del beneficio del reconocimiento de la presunción de inocencia, de la titularidad de los principios del debido proceso, del libre ejercicio del derecho de contradicción, del derecho de defensa, del principio de oportunidad, entre muchos más. La presunción de inocencia corporativa es un derecho independiente de la presunción de la persona física y no se puede alegar su beneficio, bajo resguardo del mismo derecho del individuo ${ }^{30}$.

\section{[...]. Gómez-Jara Diez, C. 2017, p. 57.}

30 Dice Gimeno Bevia que en la legislación española, es muy complicado este tema. Menciona que: [...] la posibilidad de que un mismo sujeto pueda presentar un escrito de acusación y otro de defensa en el mismo proceso, o que pueda actuar en el juicio oral en calidad de acusador y acusado, resulta -a excepción únicamente del juicio de faltas-, incompatible con la LECrim y puede generar un auténtico fraude procesal. Correspondería a los jueces y tribunales determinar en qué casos concretos y ante qué determinadas circunstancias la persona jurídica ostentara legitimación 


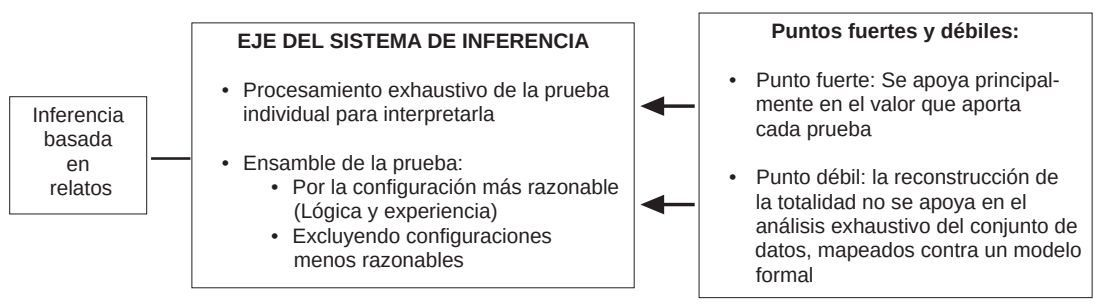

\section{F. Los conflictos de intereses entre la persona física representante y la persona jurídica}

El sistema debe tener los resguardos necesarios que eviten conflictos entre el representante de la persona jurídica en el proceso penal, cuando éste ha sido involucrado en el mismo o en otro proceso similar, por actos que puedan acarrearle responsabilidad penal individual, sin perder de vista que la obligación principal

activa para poder actuar con esa doble condición la de acusada y acusadora debiendo acotar con rigidez el contenido de sus alegaciones y proposiciones probatorias para evitar fraudes o ventajas injustificadas [...]. GIMENO BEVIA. 2016, p. 134. 
del representante es defender los intereses de la persona jurídica por sobre los intereses individuales que pueda tener. La cobertura de protección que la normativa debe priorizar son los intereses de la persona jurídica, entendida como un conglomerado de expectativas sociales, económicas, tributarias, comerciales, en el cual pueden salir afectados terceros que no son parte procesal, como es el caso de los trabajadores, socios, acreedores y el mismo Fisco.

Existe un conflicto, y muy serio, cuando los actos delictivos cometidos por el mismo representante de la persona jurídica pueden arrastrar a una condena punitiva a la corporación como consecuencia de una estrategia personal de defensa y evasión de responsabilidades. Si es el representante legal quien ha cometido el delito las actuaciones procesales claves, como la aceptación de los hechos, los acuerdos probatorios, la exclusión de pruebas, la aceptación de procedimientos abreviados, la falta de colaboración con la investigación, entre otras actuaciones, esfumarían la posibilidad de una atenuación de la responsabilidad de la corporación y expresarían un claro conflicto de intereses procesales, que terminarán afectando considerablemente el derecho de defensa de la persona jurídica en beneficio de la persona natural.

Tampoco el representante procesal de la persona jurídica podrá ser la persona natural, quién también esté involucrada en la comisión del delito que se investiga o, en su defecto, cuando haya sido llamada como testigo por la fiscalía. Sin mucho esfuerzo se puede comprender que este conflicto de intereses, distintos y contrapuestos, se podría verificar en situaciones en las que se ponga en juego la culpabilidad de la persona física y una forma de evadirla sea, a través de la entrega de documentación e 
información perteneciente a la corporación, actuación que termina en una situación de ventaja procesal en favor del representante y en contra de la persona jurídica.

En conclusión, el representante procesal de la corporación debe ser una persona que no sea testigo, ni procesado o investigado, ni otro que tenga un potencial conflicto de intereses con la organización, preferentemente elegido por algún órgano colectivo de representación de la misma persona jurídica.

\section{II.G. Los profesionales del Derecho que patrocinen a la persona física deberán ser distintos del que defienda a la persona jurídica}

Este caso, evidentemente generaría una situación delicada de indefensión, porque el abogado patrocinador de las dos personas no podría manejar objetivamente los argumentos generalmente contradictorios de la persona física procesada y los correspondientes a la estrategia de defensa de la persona jurídica.

La defensa y patrocinio legal deberán ser llevados por abogados distintos para cada una de las partes procesales precisamente para evitar todo indicio de conflictos de interés, incluso entre abogados que pertenecen al mismo estudio jurídico. 


\section{H. Las sociedades pantalla no tendrían los mismos derechos procesales que tienen las personas jurídicas}

Las sociedades pantalla son organizaciones que se crean y funcionan con el objeto de desarrollar y realizar actividades criminales. Son instrumentos al servicio de propósitos delincuenciales de los sujetos individuales quienes las conforman. Consideradas inimputables porque son sociedades muy simples y que no tienen capacidad de autogobernarse, [...] de hecho, en el caso de las sociedades pantalla se aprecia claramente que se trata de sociedades plenamente heteroadministradas, carentes de la necesaria autonomía organizativa. Por ello, la adopción de cualquier tipo de medida de intervención frente a dichas sociedades se encuentra perfectamente legitimada, si bien no se pueden considerar verdaderas penas $[. . .]^{31}$.

Nieto Martín estima que son tres los requisitos para que una organización sea autoreferencial: en primer lugar, deben encontrarse especificados claramente los requisitos para su ingreso o conformación; en segundo lugar, deben estar establecidos los mecanismos de decisión y la forma de adoptar las decisiones, previamente al establecimiento de los fines propios de la organización; $y$, en tercer lugar, cabe la identidad propia y distinta de sus miembros. Una organización debería tener una estructura jerárquica preestablecida en la toma de decisiones y,

31 Gómez-Jara, C. “¿Responsabilidad penal de todas las personas jurídicas? Una antecrítica al símil de la ameba, acuñado por Alex Van Weezel", en Revista de Política Criminal. vol. XV, N. ${ }^{\circ} 10$, diciembre de 2010. 
principalmente, un control sobre las conductas de sus miembros; en caso contrario, estaríamos frente a una sociedad pantalla ${ }^{32}$.

En estas condiciones, una sociedad pantalla no tendría derecho a ser titular de derechos fundamentales y tampoco tendría la prerrogativa de ser considerada como una persona jurídica imputable y sometida a la normativa, que rige para los procesos de determinación de la responsabilidad penal de las corporaciones ${ }^{33}$. Sin embargo, a primera vista podríamos estar frente a un caso de violación de los derechos y garantías constitucionales, de los cuales las personas jurídicas son titulares y han sido legitimadas por sendas sentencias de la Corte Constitucional, antes referidas.

No obstante, contando con la ayuda que nos presenta un desglose de la persona jurídica, realizado, por la Fiscalía General del Estado español, en la Circular 1/2016 y que para efectos de la legislación ecuatoriana, es perfectamente aplicable. Dice esta

32 Nieto Martín, A. La responsabilidad penal de las personas jurídicas: un modelo legislativo. Madrid, Iustel, 2008, pp. 166-167.

La Circular 1/2016 nos proporciona una descripción más práctica de lo que significa una persona jurídica inimputable como las sociedades pantalla. Dice textualmente: [...] junto a las sociedades que operan con normalidad en el trafico jurídico mercantil y en cuyo seno se pueden producir comportamiento delictivos existen otras estructuras societarias cuya finalidad exclusiva o principal es precisamente la comisión de delitos [...].Y Ya advertía la Circular 1/2011 que no se precisaba imputar necesariamente a la persona jurídica en aquellos casos en los que se detectara la existencia de sociedades pantalla o de fachada, caracterizadas por la ausencia de verdadera actividad, organización, infraestructura propia, patrimonio, etc, utilizadas como herramientas del delito o para dificultar su investigación. Nada impide, se dice en esta Circular, el recurso a la figura de simulación contractual o a la doctrina del levantamiento del velo [...]. Fiscalía General del Estado. 2016. 
circular que a la vista de la responsabilidad organizativa, existirían tres tipos de personas jurídicas: las primeras, son aquéllas que operan con normalidad en el mercado o en la sociedad y a las que le son exigibles los programas de cumplimiento; la segunda clase está conformada por aquéllas que desarrollan una actividad conformada, en la mayor parte, por actividades de carácter ilegal o delictivo y que mantienen cierto nivel organizativo y jerárquico. Éste es el típico caso de las empresas que realizan actividades de blanqueo de capitales; estas corporaciones todavía mantienen la categoría de personas jurídicas imputables. En tercer lugar, se encuentran las personas jurídicas totalmente inimputables. Su actividad es completamente ilegal y la persona jurídica es utilizada como un instrumento para la realización de actividades, que resultan solo disfraces de su objeto social y que está constituida por el grueso de las actividades ilegales.

Esta clasificación es importante, porque el modelo también debe contemplar la normativa, que califique de inimputable a una persona jurídica, cuando ésta sea una sociedad pantalla instrumentalizada para ocultar, tras la fachada corporativa, a la persona natural que delinque. El velo societario debe eliminarse, cuando las actividades ilegales e ilícitas de la persona jurídica ocupan la mayor parte de sus actividades.

En este contexto, reconocer derechos constitucionales a sociedades, que realizan toda su actividad por fuera de la Ley, sería dar ventaja a quienes se ocultan bajo la fachada societaria y la ley debería establecer un régimen de inocuización, a través de la disolución inmediata de estas corporaciones criminales ${ }^{34}$.

34 El autor, en relación con la inocuización, menciona que: [...] Las consecuencias jurídicas previstas para los supuestos de inimputabilidad no 


\section{II.I. La ausencia de una cultura de control y de cumpli- miento de la legalidad en la persona jurídica no debe ser un elemento del tipo y además debe ser probado por la persona jurídica y no por la acusación}

Primero dejemos en claro que la ausencia de medidas eficaces y eficientes para la prevención y control del funcionamiento interno de la corporación constituye el fundamento de la responsabilidad penal de la persona jurídica. No es el simple dato existencialista de un documento, que demuestre el funcionamiento de un compliance, para deducir de ello que existe una cultura de cumplimiento de la legalidad. Ésta consiste en la implementación, aplicación y seguimiento eficaz de sus directivas, a través del tiempo y en las circunstancias concretas, relacionadas con cada caso concreto.

Desde la perspectiva procesal, se requiere de una vez la solución al dilema de, si dogmáticamente la carencia de un programa de cumplimiento eficaz, es un elemento objetivo del tipo penal aplicable a las corporaciones y si la existencia de estas políticas concretas de prevención, constituyen circunstancias eximentes de responsabilidad penal. El apego a cualquier sistema que explique este dilema, tiene una profunda implicación procesal, especialmente relacionada con la carga de la prueba, dentro del esquema ideal propuesto.

tienen por qué ser necesariamente idénticas. Así, mientras que en el caso de empresas pantalla sería conveniente la disolución, un equivalente a la inocuización desde el punto de vista de los fines de la pena, en los supuestos de pequeñas empresas lo más adecuado es la no imposición de sanción alguna o alguna sanción de tipo estructural, como la curatela o las sanciones interdictivas [...] . NIETO MARTíN. 2008, p. 169. 
Si la existencia del compliance eficaz forma parte de la existencia del tipo penal, entonces la carga de la prueba corresponde a la parte acusadora, en este caso, la fiscalía. Es esta institución la que debe encargarse de comprobar que la persona jurídica no tiene implementado algún programa de autoregulación, para prevenir o disminuir los riesgos delictivos en la corporación.

Por el contrario, si el compliance constituye una medida de exoneración de culpabilidad, deberá ser la persona jurídica procesada, la que realice el aporte necesario de todos los elementos de convicción, que acrediten la existencia de tales programas; es decir, la teoría mayoritaria exige que sea la parte acusadora, la que acredite la inexistencia de los programas de cumplimiento, orientados a prevenir la comisión de delitos desde el interior de la persona jurídica. Este modelo reniega a que sea la parte acusadora, la que tenga que aportar elementos de juicio sobre la inexistencia de los programas de cumplimiento.

En líneas generales, el modelo propuesto exige la adopción e implementación de un compliance eficaz, que no es otra cosa que el desarrollo de un programa de cumplimiento de la legalidad. Si no existe un programa de cumplimiento eficaz para el caso concreto, entonces existe un delito corporativo y, por ende, hay lugar a la responsabilidad penal de la corporación. No es suficiente la existencia de un simple defecto organizativo como el fundamento de la responsabilidad penal de las organizaciones, sino que, en forma adicional, debe estar vinculado estrechamente con un defecto estructural, en materia de cumplimiento de la legalidad, o en relación con la cultura de cumplimiento y respeto al Derecho. 
En relación con la carga de la prueba, existe una sentencia del Ts español ${ }^{35}$, la cual es muy ilustrativa para nuestros fines, y aporta el criterio sobre cuál debe ser la actitud de la acusación, en relación con los hechos que cada parte procesal está en la obligación de aportar para la determinación de la responsabilidad de la persona jurídica. La resolución mencionada determina que el hecho propio de la persona jurídica, es decir, la eficacia o ineficacia de los programas de control y prevención de delitos implantados en las corporaciones, debe ser investigado y demostrado por el juez instructor, en nuestro caso, por la fiscalía, quien es el ente acusador.

Frente a cualquier aportación probatoria que realice la fiscalía sobre los hechos que hayan causado un déficit de supervisión, control y vigilancia, realizado desde una perspectiva general y no individualizada a todos y cada uno de los funcionarios y trabajadores de la persona jurídica, la persona jurídica podría, igualmente, aportar elementos de descargo, dada la privilegiada posición que tiene en relación con el manejo y la posesión de la prueba.

35 En este sentido, la Sentencia del TS 221/2016, de 16 de marzo, es muy clarificadora. Dice: [...] La responsabilidad penal de la persona jurídica ha de hacerse descansar en un delito corporativo, construido a partir de la comisión de un previo delito por la persona física, pero que exige algo más, la proclamación de un hecho propio con arreglo a criterios de imputación diferenciados y adaptados a la especificidad de la persona colectiva. De lo que se trata, en fin, es de aceptar que solo a partir de una indagación por el Juez instructor de la efectiva operatividad de los elementos estructurales y organizativos, asociados a los modelos de prevención, podrá construirse un sistema respetuoso con el principio de culpabilidad [...]. 


\section{J. El contenido material de la averiguación de la fiscalía en los delitos corporativos}

El objetivo de la prueba en el proceso penal ecuatoriano consta especificado en el artículo 453 COIP y se refiere a la demostración, con el grado de convencimiento, sobre la existencia material del delito y la responsabilidad del acusado. En materia de responsabilidad de las personas jurídicas, en nuestro sistema vicarial, exigiría un acoplamiento muy exigido y hasta artificial de esta normativa, con el objeto de cumplir con la demostración de la existencia del delito corporativo y de la responsabilidad de la persona jurídica.

Como la responsabilidad corporativa, en nuestro sistema vicarial extremo, se deriva de la responsabilidad de la persona física, las exigencias procesales recaen en la conducta de la persona física procesada y no en las actuaciones de la corporación, que no debería ser imputada en el mismo proceso penal.

En el sistema de responsabilidad por hecho propio, por el contrario, debe necesariamente existir procesalmente una imputación formal a la persona jurídica, notificada en la persona designada por la organización y que podría ser el representante legal. El inicio de la instrucción fiscal debe realizarse conjuntamente con la persona física, quien cometió la infracción penal, y en caso de que no haya podido ser identificada esta última, con la sola presencia de la persona jurídica.

Una vez iniciado el proceso penal, el objeto de la prueba, en relación con la persona moral, deberá ser impulsado por la fiscalía y estará orientado a la identificación de los elementos organizativos de carácter estructural, que produjeron un déficit 
de control y prevención en los programas de cumplimiento, que tienen como objetivo, precisamente, evitar la comisión de delitos al interior de la organización.

Es decir, la fiscalía está obligada, legal y constitucionalmente, a investigar, analizar, recopilar, judicializar, incorporar al proceso, mediante los medios de prueba previstos en el CoIP, todos los elementos de convicción que demuestren la falta de efectividad y de operatividad de los compliance programs, implementados por la corporación, lo que evidenciaría una falla estructural y una ausencia de una cultura de cumplimiento de la Ley, en el caso específico y concreto que se investiga.

El elemento subjetivo, para evitar una violación del principio de culpabilidad penal, se encuentra en la toma de las declaraciones, o versiones de la persona jurídica siempre y cuando se asegure que quien la represente, sea legítimamente designado por los órganos representativos de la persona jurídica. Y el contenido material de las declaraciones únicamente debe versar sobre los hechos llamados a identificar los elementos estructurales y organizativos, que provocaron el déficit de los mecanismos de prevención y control. 


\section{CONCLUSIONES}

El procedimiento penal en contra de las personas jurídicas no está establecido expresamente en el COIP. Según varios fallos de la Corte Constitucional del Ecuador, la persona jurídica es titular de todos los derechos fundamentales que goza la persona física. No obstante, partiendo del sistema vicarial vigente, la persona jurídica procesada se ve impedida del ejercicio de los derechos y garantías constitucionales, establecidos en el artículo 76 CRE, obligando a los jueces a utilizar la analogía y la interpretación extensiva como herramientas de aplicación para la determinación de la responsabilidad penal de las personas jurídicas, las cuales, a nuestro juicio, son de dudosa aceptación constitucional.

El principio de presunción de inocencia, previsto en el artículo 76.2 CRE, presume que la carga de la prueba, en los procesos penales contra las personas jurídicas -al igual que contra las personas físicas- corresponde a la fiscalía. La aplicación de la carga dinámica probatoria vendría a constituirse en un mecanismo sustitutivo, que eventualmente podría encubrir incapacidades investigativas de la fiscalía, sin que por ello en ciertos delitos, tales como el lavado de activos, el tráfico de drogas o el enriquecimiento ilícito pueda flexibilizarse, en razón de que la información que guarda el procesado, estaría en posición privilegiada de desvirtuar los cargos que se le imputan.

En el sistema de culpabilidad por defecto estructural, no es un sistema de responsabilidad penal de las personas jurídicas puro, que prescinde de la conducta de la persona física. Éste es el hecho generador de un proceso, el cual no debe confundirse con el hecho, fundamento de la responsabilidad corporativa. El delito de la persona física sirve de sustento para establecer su 
responsabilidad y es independiente de la que le impongan a la persona jurídica

Si pretendemos fundar la responsabilidad penal de las personas jurídicas en la sola existencia de un defecto de organización, tenemos un problema, porque siempre será el mismo defecto para cualquier tipo de delito, que se cometa en el seno de la corporación. El defecto organizativo por una deficiente gestión no es un hecho, sino un acto de carácter valorativo, que no tiene conexión con el resultado lesivo.

En el modelo de autorresponsabilidad ideal, que se propone para la legislación ecuatoriana, el centro gravitacional de la imputación penal a la persona jurídica es el hecho propio de la organización. En este sentido, un sistema que fomente la cultura de cumplimiento de la Ley, deviene en un sistema más adecuado de culpabilidad colectiva, que supera el modelo vicarial de transferencia. La implementación de los compliance al interior de las corporaciones constituiría un importante elemento de definición de la responsabilidad penal propia de las personas jurídicas. Su no existencia -o implementación- debe constatarse con los medios habituales de prueba, incluyendo aquélla que se pueda realizar mediante indicios.

El modelo de responsabilidad por hecho propio propuesto exige que la conducta delictiva de la persona natural, tenga una relación funcional con la corporación y que produzca beneficios para ésta. Además, se verifique la existencia de un sistema de incumplimiento de los deberes de supervisión, vigilancia y control, sin cuya omisión se hubiese podido evitar la comisión del delito con un grado de certeza. Finalmente, debe comprobarse la existencia de un defecto estructural de la organización, 
relacionada directamente con la adopción y seguimiento -o ausencia- de políticas institucionales al interior de la persona jurídica, que favorezcan la comisión de delitos. Un indicio del defecto estructural es la falta de un programa de cumplimiento eficiente y eficaz, que podría excluir la responsabilidad penal de las personas jurídicas.

La adopción de un código de cumplimiento o compliance significa el compromiso voluntario de la corporación para dirigir, conforme a éste, todas las actividades internas y externas que realiza la institución, incentivando el fiel cumplimiento de la Ley y el Derecho. Pero que en nuestro sistema vicarial extremo, el compliance no tenga ningún tipo de beneficio, o benevolencia procesal a la hora de la imputación penal en contra de la persona jurídica, es una circunstancia intrascendente, para efectos de la valoración de las pruebas en la determinación de la responsabilidad penal de las personas jurídicas, porque la conducta de la corporación no es el objeto de la prueba.

En relación con la carga probatoria, se podría proponer una alternativa, en la cual si el delito lo cometen los subordinados de la corporación, entonces la carga de la prueba de indicios tiene que ser menor, con lo cual la fiscalía debe demostrar la inexistencia o ineficacia de un programa de compliance. Por el contrario, si el delito lo cometen los miembros de la alta cúpula de la corporación y, por tanto, aquéllos que la dirigen, entonces este hecho constituye un indicio determinante de la ausencia de un programa de autoregulación eficaz para la prevención de delitos. No podríamos aplicar esta alternativa, si se insiste en que la fiscalía sea quien tenga la carga de la prueba de acreditar la ausencia de un programa de prevención eficaz. 
En el sistema de responsabilidad por hecho propio, la carga de la prueba de eficacia o ineficacia de los programas de control y prevención de delitos -compliance- debe ser investigada y demostrada por la fiscalía, quien es la institución acusadora, sin descartar el aporte probatorio de la persona jurídica como elemento de descargo de la imputación, que pesa en su contra, dada la privilegiada posición que tiene en relación con el manejo y la posesión de la prueba. 


\section{BIBLIOGRAFÍA}

BAJO FERNÁNDEZ, M., y GÓMEZ JARA-DIEZ, C. "Derechos procesales fundamentales de la persona jurídica". BAJO FERNÁNDEZ, M., FEIJÓO SÁNCHEZ, B., y GÓMEZJARA DIEZ, C. Tratado de la responsabilidad penal de las personas jurídicas. Pamplona, Editorial Aranzadi SA, 2012.

COCA VILA, I. "Programas de cumplimiento como forma de autorregulación regulada", MONTANER FERNÁNDEZ, R. (coord). Criminalidad de la empresa y compliance. Prevención y reacciones corporativas. Barcelona, Editorial Atelier, 2013.

FeIJóo SÁNCHEZ, B. El delito corporativo en el Código Penal español. Cumplimiento normativo y fundamento de la responsabilidad penal de las empresas. Pamplona, Editorial Civitas, 2016.

. "Réplica a JavierCigüela",InDret.Revistaparael análisis del Derecho. N. ' 2, 2016. Disponible en las siguientes páginas web: www. indret.com; http://www.raco.cat/ index.php/InDret/article/viewFile/314379/404485. 
.Fortalezas, debilidades y perspectivas de la responsabilidad penal de las sociedades mercantiles", OLIVEROS ALONSO, M. (coord.). La responsabilidad penal de las personas jurídicas. Fortalezas, debilidades y perspectivas de cara al futuro. Valencia, Editorial Tirant lo Blanch, 2014. Disponible también en la siguiente página web: http://www.corteidh.or.cr/tablas/usuario/ francisco.pdf.

GerstNer, M., y ALLAMAND, N. "Publicación sobre el desarrollo de la práctica de compliance en Latinoamérica. Capítulo Chile”, SERRANO, E. (coord.). Práctica de compliance en Latinoamérica. Estado actual de la legislación anticorrupción y otras. Bogotá, Autores Editores, 2015.

GIMENO BEVIA, G. Compliance y proceso penal. El proceso penal de las personas jurídicas. Pamplona, Editorial Aranzadi, Thomson Reuters, 2016.

GÓMEZ-JARA, C. "La culpabilidad de la persona jurídica", Tratado de responsabilidad penal de las personas jurídicas. Pamplona, Editorial Aranzadi S.A., 2012.

GÓMEZ MONTORO,A."La titularidad de derechos fundamentales por personas jurídicas (análisis de la jurisprudencia del Tribunal Constitucional español). Cuestiones constitucionales", Revista Mexicana de Derecho constitucional. N. ${ }^{\circ}$ 2, enero - junio de 2000. Disponible en la siguiente página web: https://revistas.juridicas. unam.mx/index.php/cuestiones-constitucionales/article/ view/5579/7243 
GOMEZ TOMILLO, M. Introducción a la responsabilidad penal de las personas jurídicas en el sistema español. Valladolid, Editorial Lex Nova, 2015.

GÓMEZ-JARA DIEZ, C. "La nueva responsabilidad penal de las personas jurídicas en el Derecho penal español (Artículo 31 bis del Código Penal)", Modelos de responsabilidad penal de las personas jurídicas. Propuestas globales contemporáneas. Lima, ARA Editores, 2012.

.La atenuación de la responsabilidad penal de las personas jurídicas", Tratado de responsabilidad penal de las personas jurídicas. Pamplona, Thomson Reuters, 2012.

GONZÁLEZ, A. "Autorregulación empresarial, ordenamiento jurídico y Derecho penal. Pasado, presente y futuro de los limites jurídico-penales al libre mercado y a la libertad de empresa", MONTANER FERNÁNDEZ, R. (coord.). Criminalidad de la empresa y compliance. Prevención y reacciones corporativas. Barcelona. Editorial Atelier, 2013.

GRACIA MARTín, L. "El Derecho penal ante la globalización económica", Cuestiones de Derecho penal, procesal penal y política criminal. Lima, ARA Editores, 2010.

NEIRA PEÑA, M. "La efectividad de los criminal compliance programs como objeto de prueba en el proceso penal", Política criminal. vol. XI, N. . 22, 2016. Disponible en la siguiente página web: https://scielo.conicyt.cl/scielo. php?pid=S0718-33992016000200005\&script=sci_arttext. 
."La prueba en el proceso penal frente a las personas jurídicas", NEIRA, A. M. (coord.). Proceso penal $y$ responsabilidad penal de las personas jurídicas. Pamplona, Editorial Aranzadi S. A., 2017.

NIETO MARTín, A. La responsabilidad penal de las personas jurídicas. Un modelo legislativo. Madrid, Editorial Iustel, 2008.

. La responsabilidad penal de las personas jurídicas: esquema de un modelo de responsabilidad penal. Madrid, Editorial Iustel, 2008.

. El Derecho penal económico en la era de la compliance. Madrid, Editorial Tirant lo Blanch, 2013.

."La responsabilidad penal de las personas jurídicas: oportunidades y retos para la cooperación judicial. Armonización del Derecho penal en la UE", Revista Europea Inklings (EUI). Año 2, N. . 2, 2013.

"La responsabilidad penal de las personas jurídicas: esquema de un modelo de responsabilidad penal", ARROYO ZAPATERO, L., y NIETO MARTÍN, A. (dirs.). El Derecho penal económico en la era de la compliance. Valencia, Editorial Tirant lo Blanch, s/f.

"Problemas fundamentales del cumplimiento normativo en el Derecho penal", KUHLEN, L., MONTIEL, J. P., y URBINA GIMENO, I. (edits.). Compliance y teoría del Derecho penal. Madrid, Marcial Pons, 2013. 
SIERRA LEWIN, S. "Las personas jurídicas en el proceso penal: experiencia chilena", PÉREZ-CRUZ MARTÍN, A. (dir.). y NEIRA PEÑA, A. M. (coord.). La responsabilidad criminal de las personas jurídicas en Latinoamérica y España. Pamplona, Editorial Aranzadi S. A., 2015.

SILVA SÁNCHEZ, J. "La responsabilidad penal de las personas jurídicas en el Derecho español”, MONTANER FERNÁNDEZ, R. (coord.). Criminalidad de la empresa y compliance. Prevención y reacciones corporativas. Barcelona, Editorial Atelier, 2013.

VILLEGAS GARCÍA, M. "Los criterios de imputación de la responsabilidad criminal de las personas jurídicas y sus efectos en los Estados Unidos de América". Tesis doctoral de la Universidad Complutense de Madrid. Madrid, 2015. Disponible en la siguiente página web: http://eprints.ucm. es/33361/1/T36458.pdf.

ZUGALDÍA ESPINAR, J., y MARÍN DE ESPINOZA, B. Responsabilidad criminal de las personas jurídicas en Latinoamérica y España. Pamplona, Editorial Aranzadi S. A., 2015.

ZUGALDÍA ESPINAR, J. Aproximación teórica y práctica al sistema de responsabilidad criminal de las personas jurídicas en el Derecho penal español. 2010. Disponible en la siguiente página web: http://www.mjusticia.gob.es/ cs/Satellite/Portal/1292343731167?blobheader=applicat ion\%2Fpdf\&blobheadername1 $=$ Content - Disposition\&b lobheadervalue $1=$ attachment $\% 3 \mathrm{~B}+$ filename\%3DPonenc ia_de_Jose_Miguel_Zugaldia_Espinar.pdf. 
.La admisión de la responsabilidad penal de las personas jurídicas: un pilar básico del moderno Derecho penal económico", MIR PUIG, S., MODOLELL GONZÁLEZ, J., GALLEGO SOLER, J., y BELLO RENGIFO, C. (coords.). Estudios de Derecho penal económico. Caracas, Editorial Librosca, 2002. 